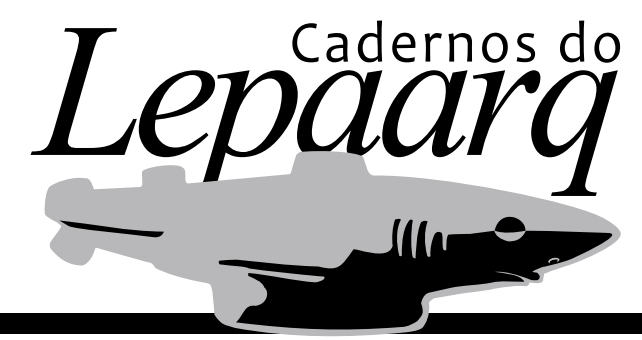

\title{
OS CERAMISTAS PRÉ-HISTÓRICOS DA PRAIA DE SABIAGUABA -
} FORTALEZA/CE.

THE PREHISTORIC POTTERS FROM SABIAGUABA BEACH - FORTALEZA/CE

Luci Danielli Avelino de Sousa Cláudia Oliveira

\section{Como citar este artigo:}

SOUSA, Luci Danielli Avelino de; OLIVEIRA, Cláudia. Os ceramistas pré-históricos da Praia de Sabiaguaba - Fortaleza/CE. Cadernos do Lepaarq, v. XVII, n.34, p. 7-25, Jul-Dez. 2020. 


\title{
Os ceramistas pré-históricos da Praia de Sabiaguaba - Fortaleza/CE
}

\author{
Luci Danielli Avelino de Sousa ${ }^{\mathrm{a}}$
}

Cláudia Oliveira ${ }^{\mathrm{b}}$

\section{Resumo:}

Este artigo apresenta os resultados das pesquisas que vêm sendo desenvolvidas nos sítios arqueológicos existentes na praia de Sabiaguaba, município de Fortaleza/CE. Trata-se do estudo da tecnologia de grupos pré-históricos que ocuparam dunas costeiras, discutindo as escolhas e as formas de exploração dos recursos naturais nesse ambiente. Procurouse caracterizar o perfil técnico cerâmico, definindo a seleção das diferentes maneiras de alcançar um fim, relacionadas a um contexto histórico. Averiguou-se a existência, a partir de uma perspectiva social, das escolhas desses grupos, presentes na forma e função dos objetos, baseada na concepção de estilo ou identidade técnica. As semelhanças identificadas na produção da cerâmica nos sítios indicam que se tratava de uma ou mais ocupações, por um só grupo ou por grupos diferentes que dominavam a mesma tecnologia.

\section{Palavras-chave:}

Sítios arqueológicos dunares; Pescadores-coletorescaçadores; Tecnologia; Cerâmica.

\begin{abstract}
:
This article presents the results of the researches that have been developed in the archaeological sites existing in Sabiaguaba beach in the city of Fortaleza/CE. It studies the technology of prehistoric groups in coastal dunes, discussing the choices and the ways of exploitation natural resources in this type of environment. We sought to characterize the ceramic technical profile, defining the selection of the different ways of reaching an end, related to a historical context. It was investigated the existence, from a social perspective, of the choices of these groups, present in the form and function of objects, based on the conception of style or technical identity. The research pointed out similarities to the same technological choices in the production of ceramics that could indicate one or several occupations referring to the same technical group.
\end{abstract}

\section{Keywords:}

Archaeological sites dune; Fishermen-collectors-hunters; Technology; Ceramics.

\footnotetext{
${ }^{a}$ Mestre em Arqueologia pela Universidade Federal de Pernambuco (UFPE)/CAPES. E-mail: lucidanielli@gmail.com

${ }^{\text {b }}$ Professora do Departamento de Arqueologia da Universidade Federal de Pernambuco (UFPE). Doutora em Arqueologia pela Universidade de São Paulo (USP). E-mail: olivas@hotlink.com
} 


\section{PESQUISAS ARQUEOLÓGICAS NA PRAIA DE SABIAGUABA}

As pesquisas arqueológicas na Praia de Sabiaguaba foram iniciadas em 2002 através do "Projeto Ponte sobre o Rio Cocó e Avenida de ligação", desenvolvido no âmbito do licenciamento ambiental, quando foram localizados os sítios Sabiaguaba I (SA I) e Sabiaguaba II (SA II). Posteriormente, através da pesquisa "Os grupos pré-históricos ceramistas da praia de Sabiaguaba, Fortaleza/CE - Brasil", realizada junto ao Programa de Pós-Graduação em Arqueologia da Universidade Federal de Pernambuco, foram localizados os sítios arqueológicos Sabiaguaba III (SA III), Sabiaguaba IV (SA IV) e Sabiaguaba V (SA V) (SOUSA, 2011).

Os sítios Gereberaba I e II foram identificados entre os anos de 2014 e 2015, através de novo projeto (MACHADO e NOBRE, 2017) integrante de licenciamento ambiental. Entretanto, os mesmos apresentam elementos técnicos que os distinguem dos demais sítios da área.

Esta pesquisa tem por finalidade delinear a tecnologia cerâmica de grupos pré-históricos que habitaram o ambiente dunar na Praia de Sabiaguaba, localizada no extremo leste do município de Fortaleza/CE, e aventar os condicionantes de suas escolhas, relacionando a técnica adotada às estratégias adaptativa ao meio litorâneo, questões ainda incipientes no contexto da pré-história do Nordeste.

Nesta fase, os estudos sobre a tecnologia foram concentrados nos sítios arqueológicos SA I e SA II, com a descrição das cadeias operatórias na produção dos artefatos (BOEDA, 2006) e a identificação das escolhas técnicas realizadas pelos grupos pré-históricos ceramistas.

Os sítios arqueológicos SA I e SA II estão localizados em área sob dupla proteção ambiental: o Parque Natural Municipal das Dunas (PNMD) a Área de Proteção (APA) de Sabiaguaba, instituídos pelos Decretos Municipais n 11.986/2006 e 11.987/2006, respectivamente. O parque mede, aproximadamente, 467.60 ha, e a APA, 1.009.74 ha (Figura 01). Essas Unidades de Conservação dispõem de ambiência com faixa praial, dunas móveis e fixas, mangue sendo banhada pelos rios Cocó e Pacoti (PREFEITURA MUNICIPAL DE FORTALEZA, 2010).

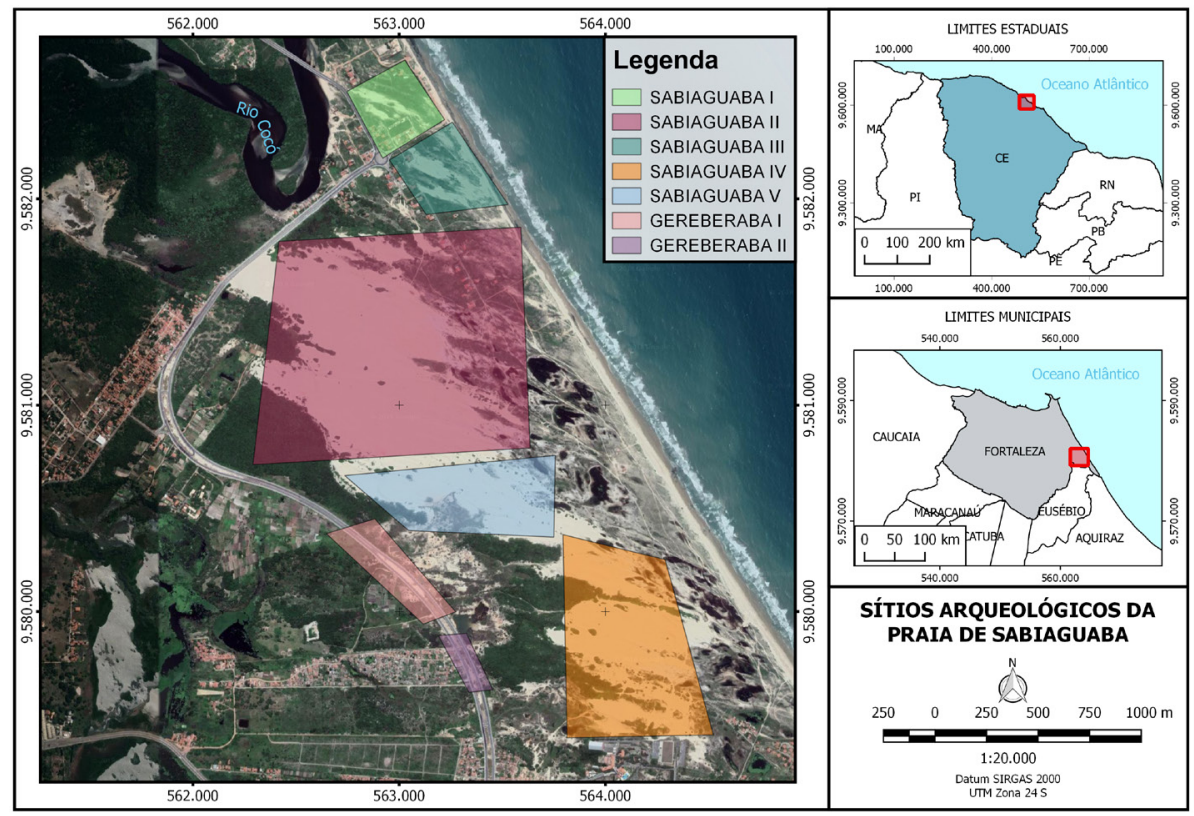

Figura 01. Área de distribuição espacial dos sítios arqueológicos na Praia de Sabiaguaba. (Mapa elaborado por Marco Sousa / Adaptado Google Earth, 2018) 
O sítio SA I (Figura 02) se encontra nas proximidades da margem direita do rio Cocó e da faixa de praia. Esse sítio é composto por 3 (três) concentrações, distando entre si de 200 a 300 m, localizado na base de corredores eólicos com vestígios líticos, cerâmicos, malacológicos (gastrópodes e bivalves) e faunísticos. Em seu entorno existe um acelerado processo de urbanização. As coordenadas das concentrações são: 0346.642' S / 038²5.993' W (conc. 1); 0346.699' S / 038²5.905' W (conc. 2); 0396.575' S / 038²5.981' W (conc. 3) (PROJETO PONTE SOBRE O RIO COCÓ E AVENIDA DE LIGAÇÃO, 2003).

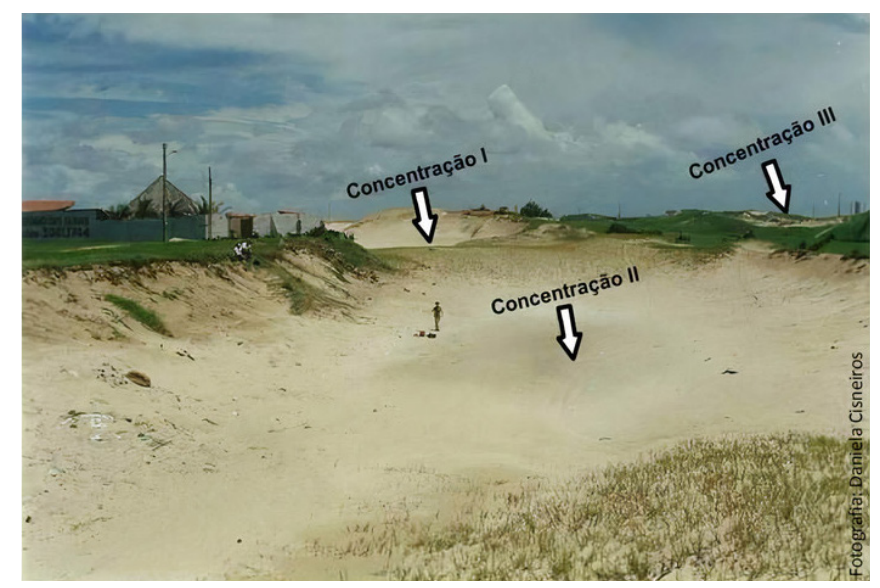

Figura 02. Sabiaguaba I com as três concentrações destacadas. (Fonte: Adaptado do PROJETO PONTE SOBRE O RIO COCÓ E AVENIDA DE LIGAÇÃO, 2003).

O sítio SA II (Figura 03) está localizado a cerca de 900 m de distância do sítio SA I e possui 5 (cinco) concentrações, com vestígios líticos, cerâmicos, malacológicos (gastrópodes e bivalves) e estruturas de fogueira. No sítio SA II, foi realizada, em 2010, a terceira campanha arqueológica, que contemplou registro topográfico, coleta de vestígios em superfície e sondagens. As coordenadas das

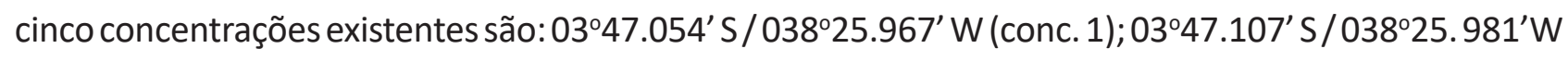

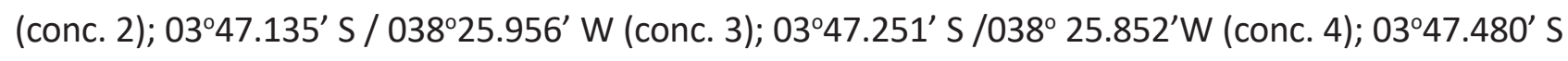
/ $038^{\circ} 25.741^{\prime}$ W (conc. 4) (SOUSA, 2011). Nesse sítio foi identificado em superfície um montículo de conchas com sedimento arenoso acinzentado e fragmentos dispersos de carvão associado a cerâmica e lítico. Essas conchas (bivalves) foram datadas por carbono 14, indicando uma ocupação humana por volta de $4.610 \pm 30$ anos BP (SAB_01_0049/Beta Anaytic/EUA). Contudo, o palimpsesto caracterizador dos sítios dunares não possibilitou relacioná-la à tecnologia existente de forma fiável.

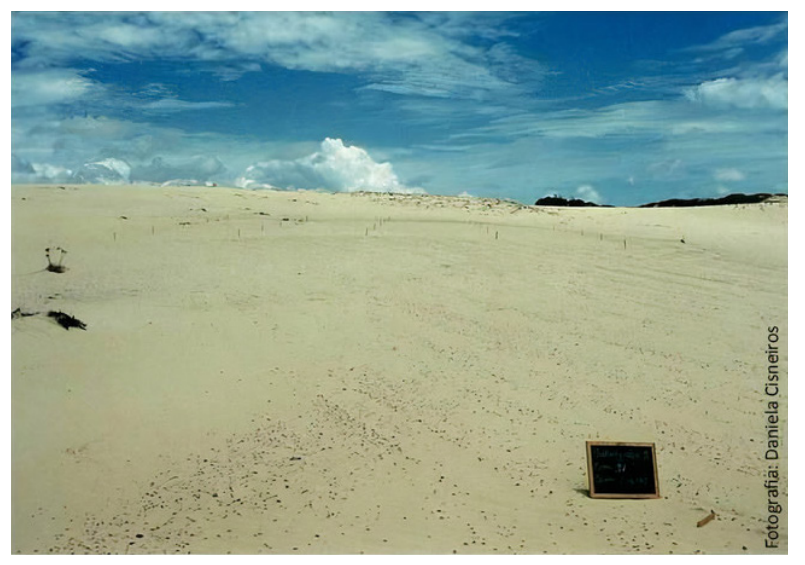

Figura 03. Sítio Sabiaguaba II destacando a mancha de lítico com o quadriculamento da coleta ao fundo. (Fonte: PROJETO PONTE SOBRE O RIO COCÓ E AVENIDA DE LIGAÇÃO, 2003). 


\section{CONTEXTO AMBIENTAL}

A ambiência dos sítios arqueológicos na Praia de Sabiaguaba apresenta faixa de praia composta pelos setores da zona de surf, estirâncio e berma, entre os rios Cocó e Pacoti.

Os terraços marinhos encontram-se entre a faixa de praia e os campos de dunas, associados a lagoas intermitentes. Essa unidade morfológica apresenta descontinuidade na desembocadura dos rios Cocó e Pacoti. No terraço marinho, ocorrem lagoas costeiras relacionadas à variação do nível hidrostático, associadas as dunas semifixas vegetadas.

O processo de deflação promove a movimentação em campos de dunas, que pode evidenciar os aquíferos, originando lagoas, bem como expor vestígios arqueológicos. A movimentação dos sedimentos forma dunas com areia interceptada a barlavento de pontas litorâneas. Esse processo de movimentação, denominado de by-pass costeiro, gera grandes campos de dunas.

Segundo Meireles, Silva e Raventos (2001), na praia de Sabiaguaba são identificadas dunas fixas (parabólicas e transversais) e dunas em formação sobre a zona de berma e terraços marinhos, recobrindo os arenitos de praia, que, por conseguinte, são de período mais recente.

As dunas são indicadores de alterações paleoclimáticas e paleogeográficas de períodos de maior disponibilidade de sedimento e aridez, durante os processos de regressão que sucedem períodos de transgressão marinha. De acordo com estudos realizados na costa brasileira, o máximo da última transgressão marinha foi datado de \pm 5.600 anos AP. Por sua vez, as pesquisas arqueológicas nas regiões Sul e Sudeste referentes aos grupos sambaquieiros apontam para o início das ocupações na costa a partir desse período, quando se formaram extensas lagunas, posteriormente à transgressão marinha (SILVA, 2001).

Os sítios arqueológicos SA I e SA II estão assentes entre a planície de deflação e o campo de dunas móveis (Figura 04).

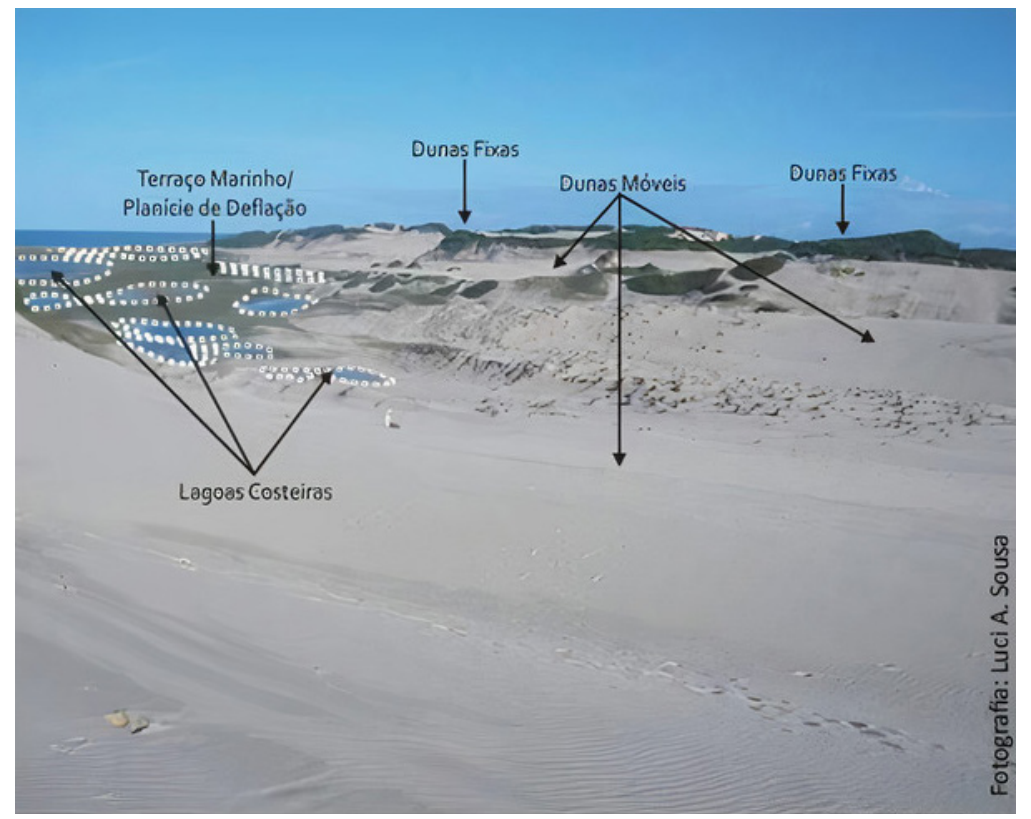

Figura 04. Planície de deflação e campos de dunas (SOUSA, 2011). 
Os sítios arqueológicos dunares permitem a preservação de seu contexto devido ao rápido soterramento promovido pela dinâmica de movimentação típica desse ambiente; porém, a deflação provoca a fusão de distintos testemunhos de ocupações pretéritas em um único solo (BUTZER, 1989), incidindo no palimpsesto caracterizador dos sítios dunares com movimentação vertical e horizontal dos vestígios arqueológicos.

\section{AS ESCOLHAS TÉCNICAS}

A cultura material possui, em si, informações sobre o contexto do qual é resultante, bem como sobre as atividades relacionadas à sua produção. Essas informações podem ser observadas através dos objetos, nos quais estão presentes as escolhas técnicas realizadas pelos grupos humanos em determinado tempo e espaço.

De acordo com Pfaffenberger (1992), a técnica corresponde àquilo que se refere ao sistema de recursos materiais disponíveis, as ferramentas, as sequências de operações e, por fim, as habilidades do conhecimento (verbal e não-verbal) de modelos específicos necessários para produzir o artefato. Considera-se, portanto, que cada grupo que interage em determinado tempo e espaço possui conhecimento dos procedimentos técnicos e comportamentos que envolvem a transformação da natureza em objetos utilitários, sendo esses elementos portadores de um estilo técnico.

O estilo tecnológico estaria relacionado às escolhas empreendidas pelo artesão desde a obtenção da matéria-prima até o acabamento final, constituído do resultado de uma tradição cultural. Dessa forma, o estilo tecnológico "pode servir como indicador de identidades sociais ou culturais presentes no registro arqueológico" (DIAS, 2003, p. 45).

Para Oliveira (2008, p. 161), o estilo tecnológico envolve "as escolhas tecnológicas da matériaprima, as formas, a função, o modo de fazer e de pensar, que reflete um contexto histórico", o qual poderá demonstrar ou não significados simbólicos.

Conkey (1990) acrescenta que o estilo transcende a história dos objetos e os atributos formais, contemplando a história das representações sociais em que estão imersos os objetos. 0 estilo volta-se para a variabilidade e os sistemas culturais investigados através da cadeia operatória, forma, função e design. O design é mais que um atributo formal do objeto, mas um conjunto de processos essenciais escolhido pelo artesão que fornecem à forma sua existência.

Conforme Sackett (1990), o estilo é construído e não adicionado ao objeto. No estilo ativo, o artesão possui a intenção de identificar-se e manter os limites entre os grupos sociais, enquanto, no estilo passivo, não há intencionalidade de delimitar limites, sendo inerente nas escolhas isocréticas que estão por trás da manufatura do objeto.

O grupo técnico, segundo Leroi-Gourhan (1984), corresponderia a uma parte do grupo étnico, o qual seria a expressão material de um meio interno contínuo. O grupo técnico assinala a "materialização das tendências que atravessam o meio técnico" (1984, p. 263). Nessa perspectiva tecnológica, Fagundes (2004) destaca que existe uma identidade técnica, com a premissa de que há uma herança social na produção de um dado artefato. Os artesãos produzem, em distintos 
contextos espaço-temporais, artefatos seguindo o conhecimento adquirido. Esta identidade técnica foi denominada por Fagundes (2004) como estilo.

A identidade, portanto, concerne a um elemento que diferencia um grupo de outro e permeia o universo de representações, nas quais se inserem as práticas de significações e o sistema simbólico, sendo através das representações que os significados são produzidos. A identidade é uma construção simbólica e social, cuja afirmação impele causas e consequências materiais (WOODWARD, 2009).

Segundo Lemonnier (1983), a ação do homem sobre a matéria revela a técnica a qual permite analisar três ordens de fenômenos: o objeto propriamente dito, os processos que envolvem a cadeia de operações oriunda do reagrupamento das sequências de gestos praticados na manufatura do objeto, e o conhecimento do nível de domínio técnico do artesão.

A transformação do meio seria, portanto, o resultado do processo de adaptação cultural através do desenvolvimento da capacidade técnica do homem, diante do processo contínuo de interação cultural. Desse modo, não se pode separar, no objeto, a forma e a função, pois estão associadas às necessidades do grupo, ou seja, às construções sociais.

Por outro lado, o processo de produção abrange toda uma cadeia de atividades desenvolvidas que tem início na captação da matéria-prima, na manufatura do objeto, seu uso, reaproveitamento e descarte (BRÉZILLON, 1968; INIZAN; REDURON-BALLINGER, ROCHE E TIXIER, 1995; LEMONNIER, 1983; SCHIFFER E SKIBO, 1997; SHIFFER, 1972).

Nesta pesquisa, buscou-se distinguir, a partir da técnica, a seleção das diferentes maneiras de se alcançar um fim, relacionando-a a um contexto histórico e à existência de uma perspectiva social da escolha da forma e função dentro de uma concepção de estilo. Conforme James Sackett (1990), a técnica é vista como uma variação isocrética, na qual é impossível haver recorrência de forma e desenho, nos diferentes contextos históricos.

A delimitação de diferenças técnicas nos vestígios arqueológicos possibilita o estabelecimento de limites de domínio técnico, representando distintas origens e processos produtivos. Essas distinções nos perfis técnicos indicam a existência de estilos técnicos próprios que poderiam estar relacionados a grupos culturais diferentes (OLIVEIRA, 2009).

Nesse sentido, investiga-se primeiramente o perfil técnico em determinado contexto histórico, no qual são definidas as escolhas técnicas de um determinado grupo pré-histórico. Assim, o perfil técnico é visto como uma estrutura onde os seus elementos ou atributos estão organizados de forma hierarquizada pelas escolhas técnicas, que define dado Sistema Técnico de um grupo (OLIVEIRA, 2000). Portanto, a identificação de perfis técnicos e da relação entre os mesmos em uma determinada área e período de tempo permite a delimitação de tecnologias arqueológicas e padrões de comportamentos sociais.

O perfil técnico é, por conseguinte, um instrumento para definir um estilo tecnológico, estando esse relacionado às escolhas empreendidas pelo artesão na obtenção da matéria-prima, na produção e no uso dos objetos de uma determinada tradição tecnológica.

Nesta perspectiva metodológica, o perfil técnico definido em um sítio arqueológico seria formado pela relação dos perfis técnicos (cerâmico, lítico e gráfico), enquanto o sistema técnico de 
determinado grupo pré-histórico seria constituído de um conjunto de perfis técnicos de vários sítios comparados entre si (OLIVEIRA, 1990, 2003). Buscou-se, portanto, estabelecer os perfis técnicos dos sítios SA I e SA II e discutir como os objetos produzidos permitem inferir sobre as necessidades e as construções sociais desses grupos. Desta feita, intenta-se identificar a sequência de gestos para produção dos artefatos, o nível do domínio técnico e às necessidades específicas de grupos pré-históricos da praia de Sabiaguaba.

\section{ASPECTOS DA TECNOLOGIA DOS GRUPOS PRÉ-HISTÓRICOS DE SABIAGUABA}

Dentro da proposta de delimitar a relação do homem com seu meio a partir da tecnologia foi traçado o perfil técnico dos respectivos sítios. Esse perfil foi caracterizado pelos elementos técnicos, morfológicos, funcionais e de design. Os elementos técnicos correspondem às técnicas de produção dos objetos, como as escolhas da matéria-prima, os instrumentos utilizados e as técnicas de manufatura. Os elementos da forma estão relacionados ao tamanho, ao tipo e à variabilidade morfológica que irão caracterizar os elementos do design, ou seja, quais elementos técnicos e morfológicos foram escolhidos por cada grupo. Por fim e, o mais complexo de inferir em um perfil técnico são os elementos funcionais, pois além do contexto arqueológico, é necessário, em muitos casos, a utilização de métodos físico-químicos para a sua identificação. Esses elementos permitem descrever os procedimentos da cadeia operatória ou a sequência de produção e uso dos artefatos. A organização tecnológica alude, portanto, à relação das escolhas do artesão com a performance do artefato, ou seja, as sequências das atividades na produção são regidas pela performance de cada artefato e dos gestos necessários para sua produção (SCHIFFER E SKYBO, 1997; OLIVEIRA, 2000).

A análise dos vestígios cerâmicos seguiu os procedimentos metodológicos utilizados em vários sítios arqueológicos no Nordeste (CASTRO, 1999; OLIVEIRA, 2000; SOUSA, 2011), considerando-se os diferentes níveis de informações dos vestígios arqueológicos. Após a higienização e numeração da cerâmica, os fragmentos foram agrupados em unidades definidas pelo tipo de pasta e tratamento de superfície, com a finalidade de buscar associações que tornassem possíveis a reconstituição dos objetos. Nessa fase, trabalhou-se com dois conjuntos de dados: a) as informações obtidas através dos fragmentos que não puderam formar objetos, identificando-se os aspectos referentes à técnica e as matérias-primas; b) as informações obtidas no conjunto dos objetos reconstituídos, que permite alcançar a relação entre tecnologia, forma, design e função desses objetos.

Os fragmentos foram reunidos em 4 tipos de pastas: Pasta 1 com antiplástico ${ }^{1}$ de areia (grãos $<1 / 4 \mathrm{~mm}$ ) e textura fina; Pasta 2 - de areia $(1 / 2 \mathrm{~mm} \leq$ grãos $<2 \mathrm{~mm}$ ) com textura mediana; Pasta 3 com areia (grãos $>2 \mathrm{~mm}$ ) e textura grosseira; Pasta 4 com bolo de argila acrescido de areia com textura média e fina (Figura 05).

1 Elementos existentes ou adicionados à argila que reduzem a plasticidade da mesma (LA SALVIA; BROCHADO, 1989). 


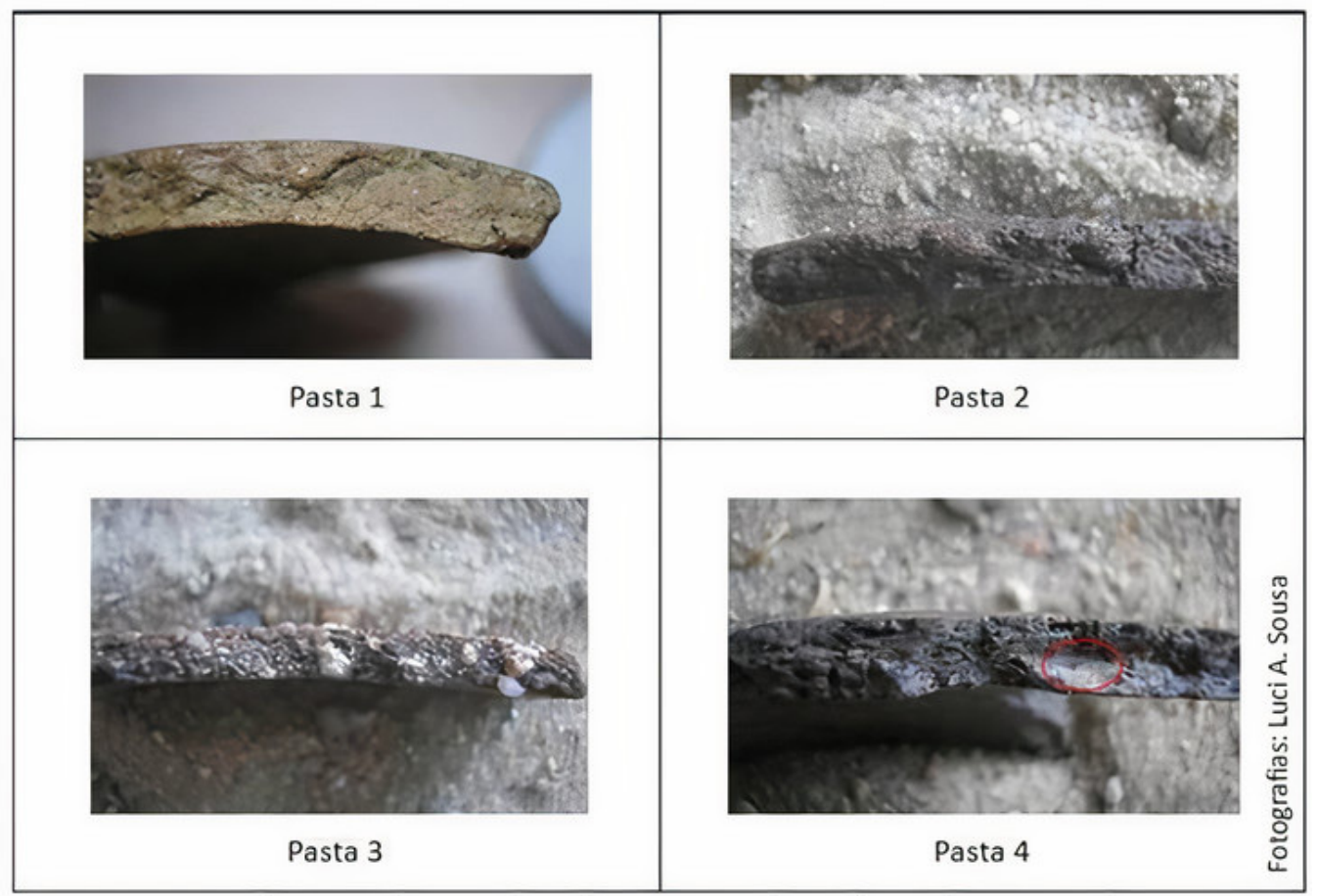

Figura 05. Granulometria dos grãos nas pastas das cerâmicas (SOUSA, 2011).

No tratamento de superfície ${ }^{2}$ foi considerado o acabamento final realizado na peça, incluída a decoração. No caso da decoração plástica, observou-se o alisado e o polido, além da decoração não plástica, como a pintura (vermelho e banho da própria argila) e o brunido (Figura 06).

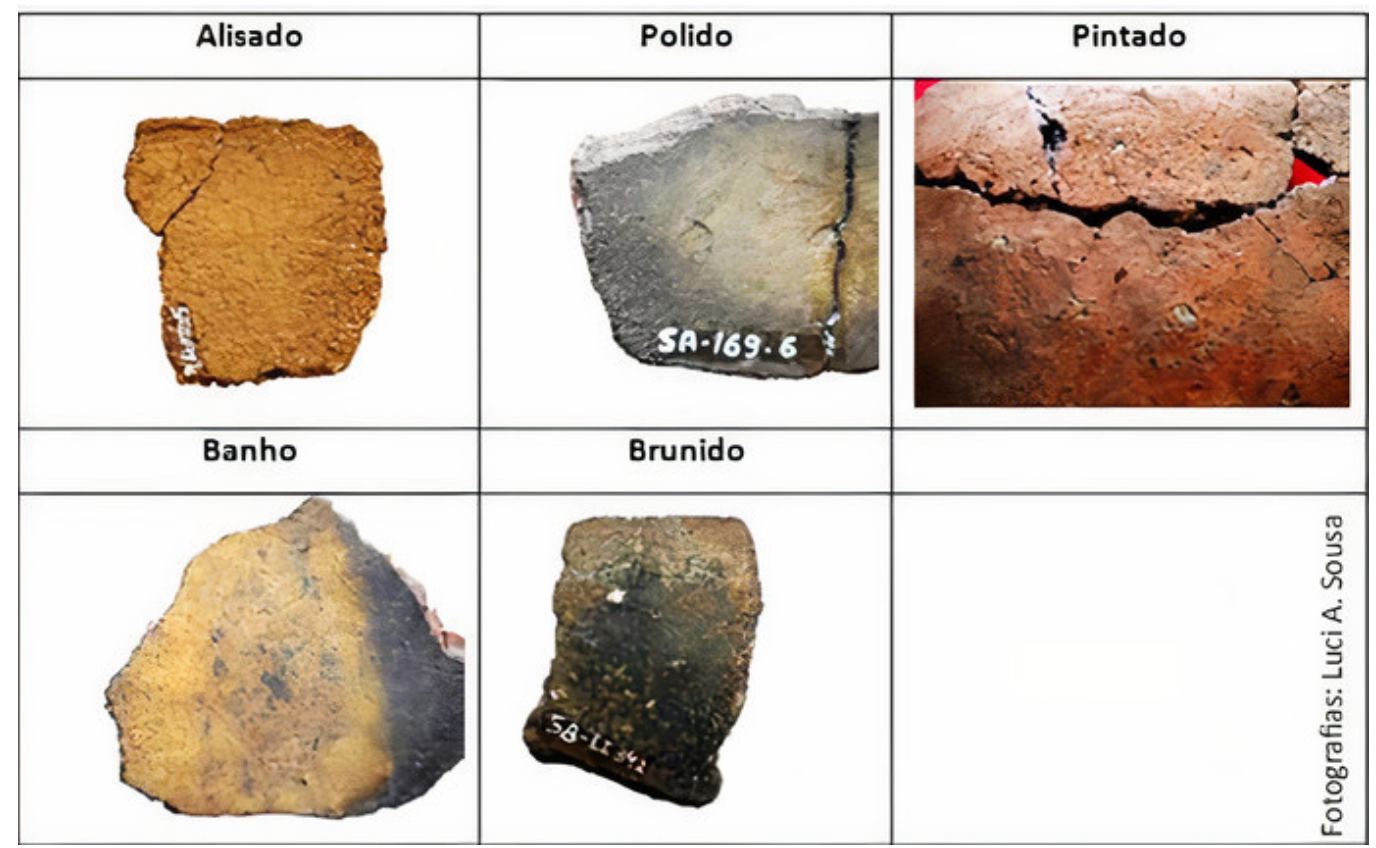

Figura 06. Tipos de tratamento de superfície (SOUSA, 2011).

2 Tratamento de superfície ou técnicas de acabamento de um objeto, neste caso, inclui também as técnicas de decoração, tradicionalmente definidas como pintada ou plástica. 
Os objetos foram agrupados em cachimbos e vasilhas. A reconstituição hipotética das vasilhas levou à sua subdivisão em sete grupos (Figura 07), segundo a sua forma ${ }^{3}$ (SHEPARD, 1961; MEGGERS, EVANS; 1970, OLIVEIRA, 2000), a saber:

Forma 1: tigela de forma ovoide 1 - vasilha aberta, contorno simples, paredes extrovertidas, boca ampliada, altura menor ou igual à metade do diâmetro.

Forma 2: tigela de forma ovoide 2 - vasilha aberta, contorno simples, paredes extrovertidas, boca ampliada, altura maior que a metade do diâmetro da boca.

Forma 3: tigela de forma esférica 1 - vasilha aberta, contorno simples, boca constrita, paredes retas, altura menor ou igual à metade do diâmetro da boca.

Forma 4: tigela de forma elipsoide horizontal - vasilha fechada, contorno simples, boca constrita, paredes introvertidas, altura igual ou menor à metade do diâmetro da boca.

Forma 5: panela de forma ovoide 3 - vasilha fechada, contorno simples, paredes introvertidas, boca constrita, altura maior que à metade do diâmetro da boca.

Forma 6: panela de forma esférica 2 - vasilha fechada, contorno simples, boca constrita, paredes introvertidas, altura maior que à metade do diâmetro da boca.

Forma 7: tigela de forma esférica 3 - vasilha fechada, contorno infletido, boca ampliada, paredes introvertidas, altura maior que à metade do diâmetro da boca.

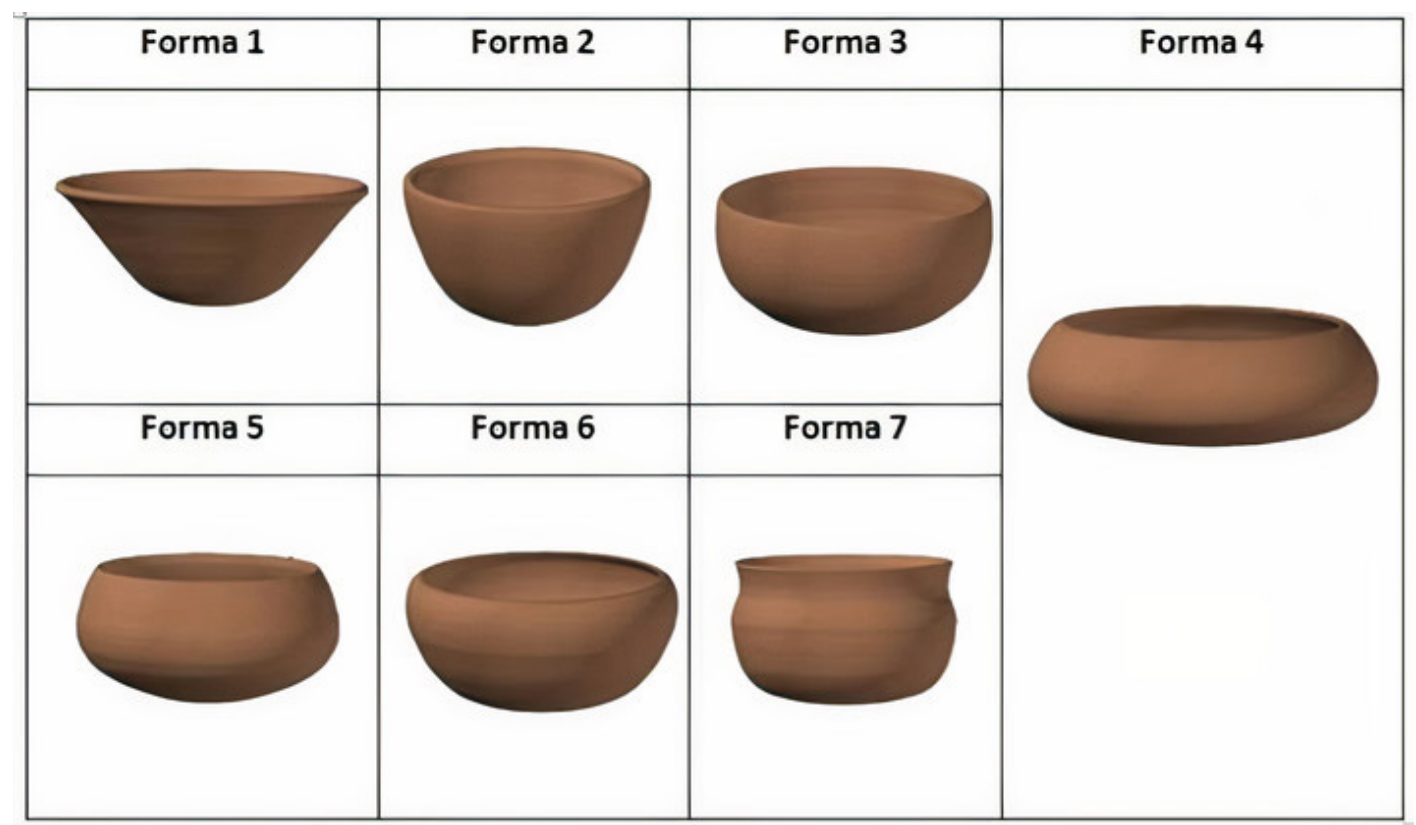

Figura 07. Formas das vasilhas resconstituídas (SOUSA, 2011).

As vasilhas foram divididas de acordo com tamanho em: pequeno (volume de $0,15 \mathrm{dm}^{3}<1$ $\mathrm{dm}^{3}$ ), médio (volume de $1 \mathrm{dm}^{3}<4 \mathrm{dm}^{3}$ ) e grande (volume de $4 \mathrm{dm}^{3}<16 \mathrm{dm}^{3}$ ).

3 De acordo com a classificação de Brochado (1977) das categorias morfológicas, as vasilhas foram classificadas em: panelas (altura igual ou maior que o diâmetro máximo) e tigelas (altura igual ou menor que o diâmetro máximo). 
No que concerne aos critérios utilizados para se deduzir a funcionalidade das vasilhas, foram observados os traços de desgaste e marcas de fuligem decorrentes do uso, bem como informações etnográficas e etnoarqueológicas.

Nos sítios dunares os vestígios arqueológicos ficam expostos a um intenso processo erosivo que afeta diretamente a quantidade dos vestígios a serem analisados, principalmente, no caso da cerâmica pré-histórica (Figura 08). Para o estudo do processo de produção da cerâmica foram considerados os fragmentos com a superfície interna e/ou externa não erodida. No sítio SA I, do total de 390 fragmentos encontrados, foram analisados 211 , ou seja, $54 \%$ do total. No sítio SA II ocorreu um processo erosivo mais intenso, dos 1.172 fragmentos existentes apenas 31\% da amostra foi analisada, totalizando um universo de 363 fragmentos.

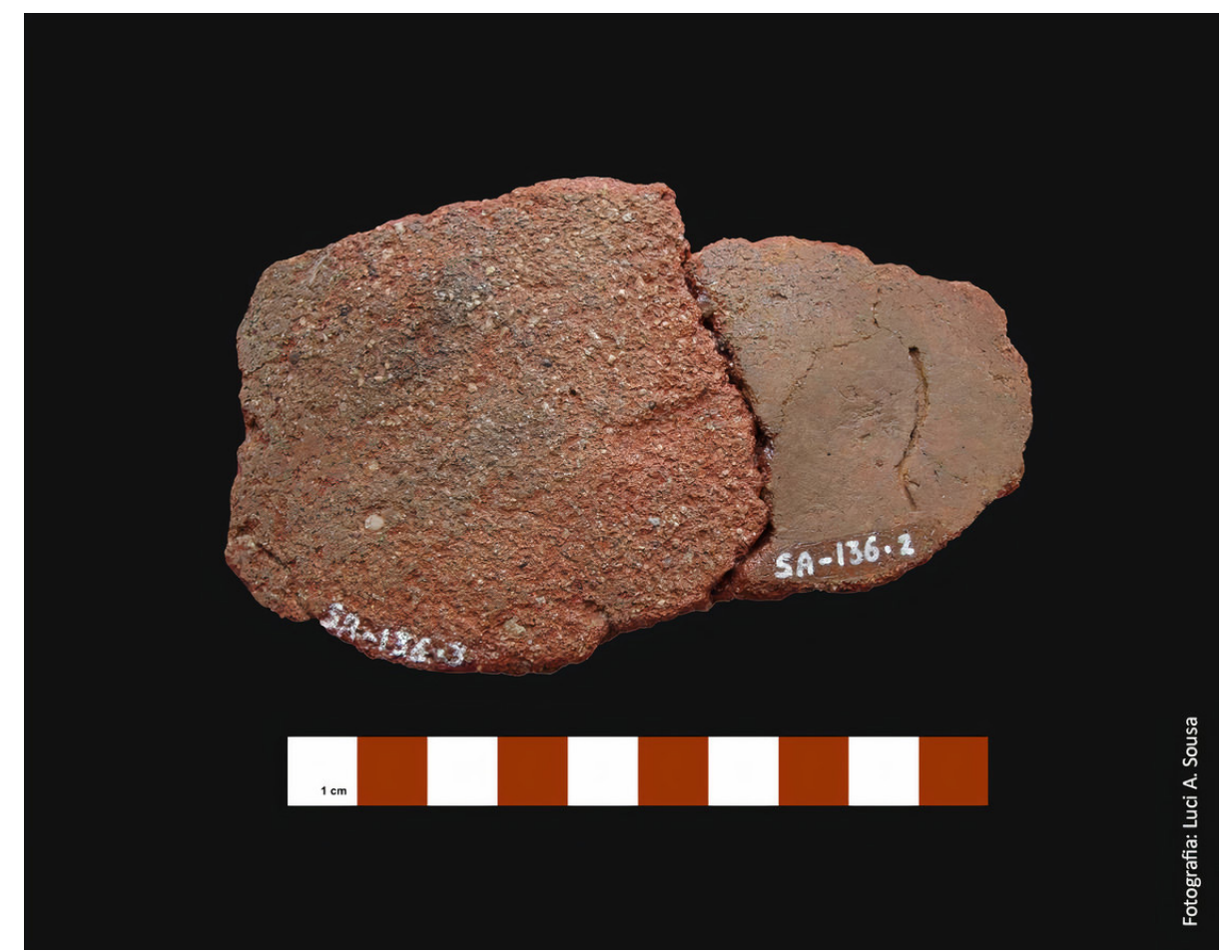

Figura 08. Fragmento de cerâmica resconstituída com superfície erodida (SOUSA, 2011).

Os perfis cerâmicos dos sítios SA I e SA II apresentam as seguintes semelhanças: cerâmica com espessura média em torno de $0,5 \mathrm{~cm}$, variando entre $0,3 \mathrm{~cm}$ a $1,8 \mathrm{~cm}$; predomínio da produção de vasilhas com uso de uma pasta "grosseira", com grãos de quartzo e feldspato maiores que $2 \mathrm{~mm}$, havendo proporção grande de areia em relação à argila, embora os ceramistas tenham produzido também, numa frequência menor, vasilhas com bolo de argila.

Uma pasta com maior quantidade de antiplástico exige um melhor controle do artesão, pois o manuseio se torna difícil. Os grãos de quartzo aumentam a porosidade da vasilha, permitindo maior resistência a choque térmico; em compensação, geram fraturas quando da exposição contínua ao fogo de vasilhas que, no processo de manufatura, não receberam cocção completa (RYE, 1981).

Os grãos de antiplástico com tamanho maior podem ter sido intencionalmente acrescidos à argila excessivamente plástica, ou indicariam a característica do depósito utilizado com ausência de seleção dos grãos através do peneiramento da pasta a priori. 
As técnicas de manufatura identificadas foram modelado e acordelado, com dureza inferior a 2,5 da escala de Mohs, portanto, uma queima incompleta à baixa temperatura, que se verifica na maior parte dos fragmentos. Isso explicaria o alto índice de cerâmica erodida nesses sítios. Salientamos que a dureza é influenciada pelo tipo de queima, porosidade da cerâmica, distribuição dos grãos, processos pós-deposicional e composição do mineral (ORTON; TYERS; VINCE, 1997).

Com a finalidade de identificar a temperatura de queima e o tipo de argila utilizada na produção da cerâmica, recorreu-se à Difratometria de Raio X (DRX). Para esse estudo, foram selecionadas 5 (cinco) amostras (três do sítio SA I e duas do sítio SA II) as quais passaram por duas análises de difratograma ${ }^{4}$. Houve a necessidade do uso de distintas técnicas de preparação da amostra, pois, na primeira análise, não foi possível verificar a presença de argilominerais. Na segunda análise de difratograma, as amostras foram submetidas à técnica de decantação para separar por densidade as partículas de argilominerais (Figura 09).

Na primeira análise qualitativa dos difratogramas foi possível verificar a similaridade dos minerais presentes na pasta das cerâmicas: Quartzo $(Q)$, Ortoclásio (O), além de um mineral não identificado pertencente ao grupo Anfibólio. Na segunda análise, foi constatada a presença de argilomineral, provavelmente esmectita ou vernículita, no sítio SA II.
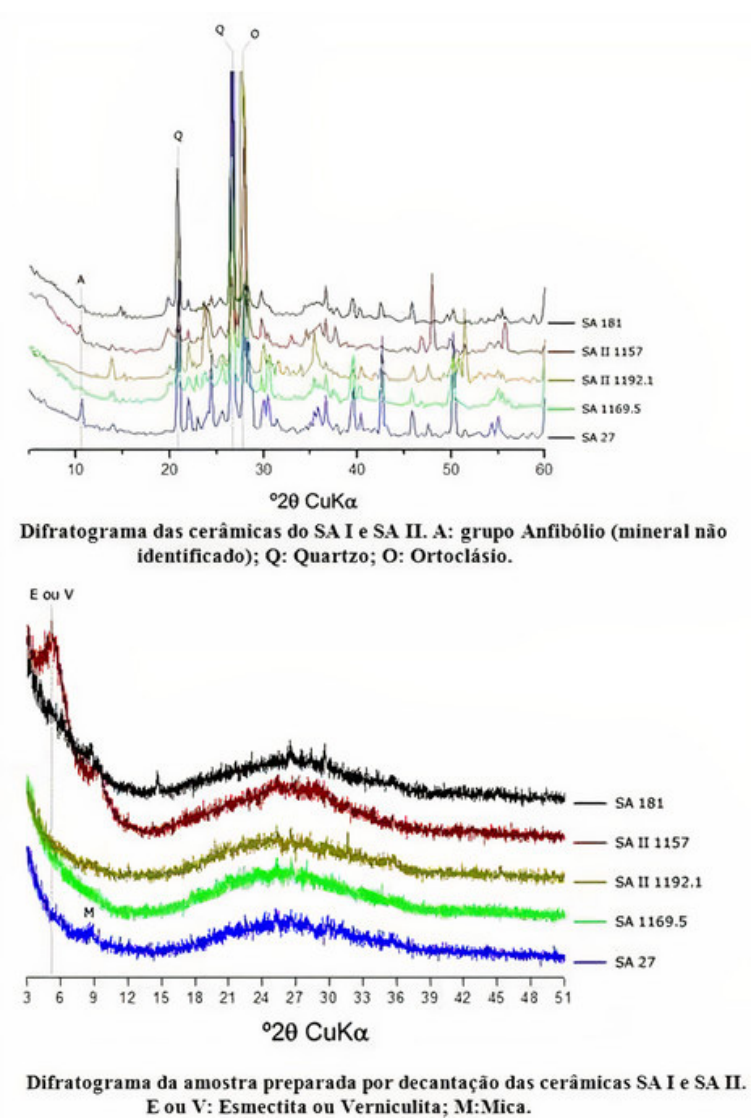

Figura 09. Difratograma das amostras de cerâmica (SOUSA, 2011).

\footnotetext{
$4 \quad$ A difratometria foi realizada no Laboratório de Ensaios Não-Destrutivos (LABEND), do Departamento de Engenharia de Minas, da UFPE, sob orientação da Profa. ${ }^{\text {. Dra }}$. Lucila Ester P. Borges e no Laboratório de Mineralogia de Solo, do Departamento de Agronomia, da UFRPE, sob orientação do Prof. Dr. Valdomiro Severino de S. Júnior. O equipamento utilizado foi o Difratograma de Raio-X Shimadzu XRX 6000 com radiação de cobre (CuKa), potencial de 40 kV e corrente de $4 \mathrm{~mA}$.
} 
A cerâmica analisada apresenta dois tipos de queima, havendo predomínio quantitativo da queima incompleta. A partir da análise de Difratometria de Raios $X$ foi averiguada, em quatro amostras, a ausência de argilominerais na composição da pasta. Os estudos realizados por Alves (1994), Pinheiro e Holanda (2010) mostram que as temperaturas de queima podem ser inferidas pela transformação dos argilominerais em diferentes temperaturas. Conforme Leite (apud Alves, 1994), a caulinita, ao ser submetida a temperatura acima de $550^{\circ} \mathrm{C}$, torna-se amorfa e desaparece do difratograma. Não obstante o número reduzido de amostras, os dados obtidos sugerem que a cerâmica teria sido queimada a temperatura acima de $550^{\circ} \mathrm{C}$ e que teria sido utilizada na sua produção uma argila do tipo caulinita.

As vasilhas possuem o tratamento de superfície alisado, polido e pintado de vermelho sem motivos decorativos, bem como banho de argila, com bordas diretas e as bases convexas. Algumas vasilhas apresentam boca ampliada e constrita com contorno arredondado. Segundo Rye (1981), as vasilhas para cozinhar que possuem contorno arredondado têm maior resistência aos choques térmicos. Neste conjunto foram feitas vasilhas de tamanhos médio e grande, pintadas de vermelho, com lábios arredondados, havendo o predomínio de tigelas em relação às panelas.

Alguns elementos característicos da tecnologia cerâmica dos grupos pré-históricos das dunas apareceram, até o momento, apenas em um sítio. Isso ocorreu com o tipo de tratamento de superfície brunido, verificado apenas no sítio SA II. Essa técnica utiliza um tipo de resina orgânica na superfície da vasilha, o que proporciona a impermeabilização da cerâmica evitando que o líquido armazenado infiltre ou percole na vasilha, podendo indicar a utilização de vasilhas para cozinhar ou armazenar água (RYE, 1981).

No sítio SA I foi encontrado um fragmento de cachimbo (Figura 10) e uma vasilha com perfuração circular no bojo (Figura 11). A presença de um cachimbo denota o consumo do fumo pelo grupo e a perfuração no bojo pode apontar para o uso de alça e a necessidade de transportar as vasilhas.
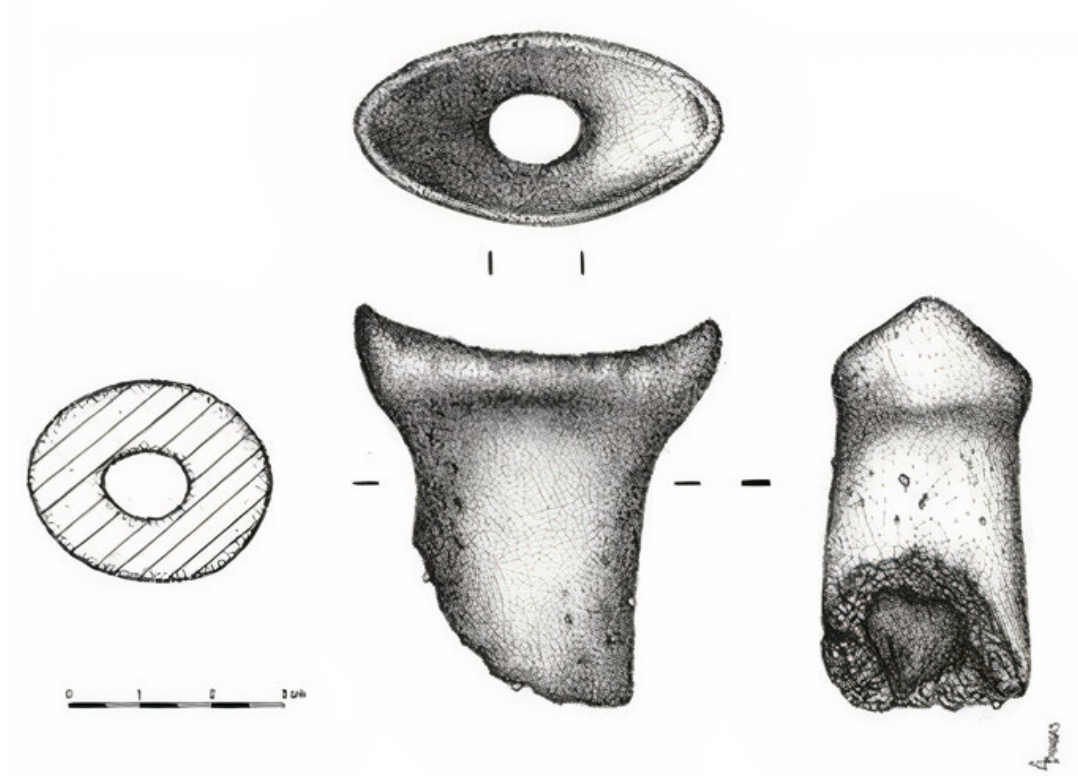

Figura 10. Cachimbo (Desenho: Angélica Borges) (SOUSA, 2011). 


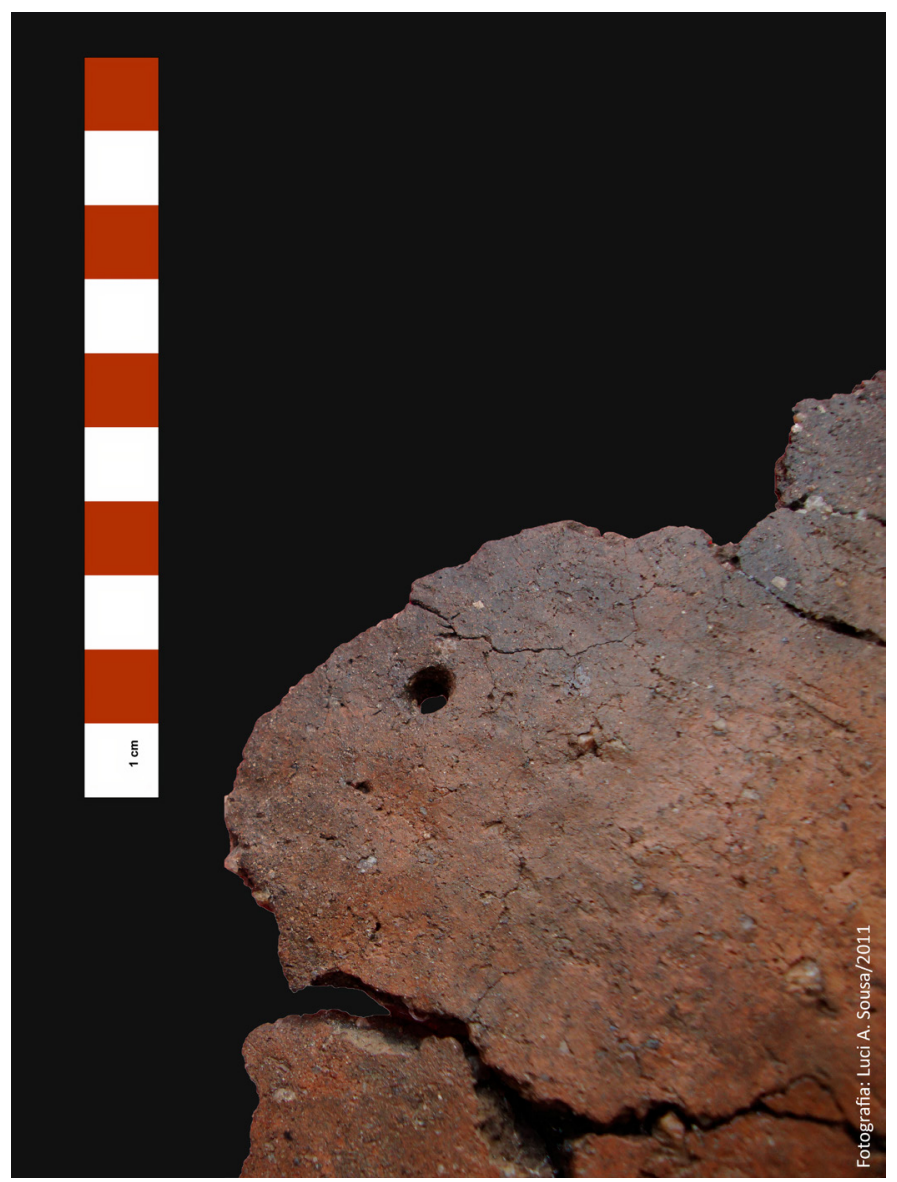

Figura 11. Furo no bojo da vasilha, sítio SA I (SOUSA, 2011).

Alguns fragmentos apresentam marcas de fuligem, devendo proceder de vasilhas utilitárias, assim como desgastes nas extremidades, sugerindo a reutilização da cerâmica; no último caso, os estigmas apontam o uso da peça como polidor (Figura 12).

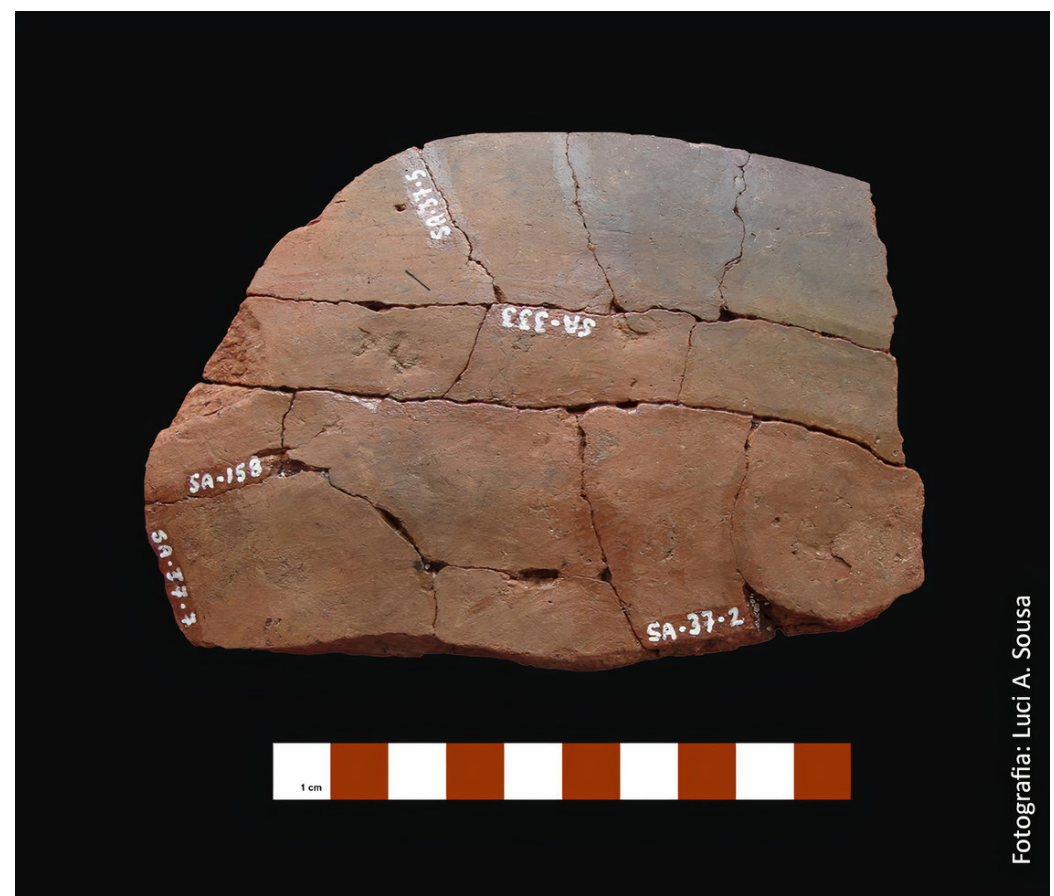

Figura 12. Marcas de reutilização da cerâmica (SOUSA, 2011). 
Apesar do universo reduzido de fragmentos cerâmicos, verifica-se que, de modo geral, a variação na tecnologia cerâmica entre os sítios SA I e SA II é pequena, sendo mais quantitativa do que qualitativa. As vasilhas possuem tamanhos pequeno, médio e grande, entretanto, as vasilhas de tamanho pequeno existem apenas no SA II. Nesse sítio existem também vasilhas de borda extrovertida e a presença maior de panelas e vasilhas de boca ampliada. Contudo, essas diferenças podem estar mais relacionadas a diferentes atividades do que a diferentes tecnologias entre os sítios. A similaridade tecnológica nos SA I e SA II pode apontar para contemporaneidade entre as ocupações e a persistência nas escolhas técnicas.

\section{CONSIDERAÇÕES FINAIS}

Os estudos de sítios arqueológicos dunares representam desafios metodológicos para os pesquisadores. A ausência de estratigrafia que viabilize distinções cronológicas de ocupação e o reduzido número de dados arqueológicos de sítios em dunas no Nordeste brasileiro são alguns dos problemas enfrentados na pesquisa nessa área.

Os vestígios arqueológicos de Sabiaguaba, de forma geral, sofreram intenso processo de alteração devido a agentes erosivos, acarretando a ausência de contextos arqueológicos e a fragmentação da cerâmica. Esses problemas limitaram as informações da coleção arqueológica analisada e, naturalmente, o conhecimento da tecnologia e de outros aspectos culturais.

No estudo do sistema técnico, buscamos conhecer as escolhas do grupo e de gestos apreendidos através da observação, repetição e ensaios, correspondendo aos comportamentos comuns a um determinado grupo, e presentes na escolha da matéria-prima até o produto final. Essa sequência ordenada de atos, verificada na cadeia operatória de produção, resulta dos conhecimentos sociais que são particulares de uma identidade tecnológica.

Nos perfis técnicos dos sítios SA I e SA II, destacamos a produção de vasilhas com as técnicas modelada e acordelada, paredes finas, pasta de antiplástico de areia e, eventualmente, areia com bolo de argila. Essas vasilhas eram alisadas, pintadas, polidas e brunidas com formas de bocas abertas e constritas, arredondadas, compreendendo tigelas e panelas, nos tamanhos grande, médio e, ocasionalmente, pequeno.

Em relação à função dessas vasilhas, ressaltamos a presença de indícios do uso para cozinhar, devido os resquícios de fuligens identificados em algumas peças. Essas vasilhas podem ter sido utilizadas para processar iguarias particulares do ambiente costeiro, considerando a presença de vasilhas grandes e de malacológicos em ambos os sítios. No entanto, são necessárias análises físico-químicas, como a cromatografia gasosa, para identificar os biomarcadores e possíveis tipos de alimentos que, por sua vez, indicariam, com exatidão, aspectos da dieta alimentar desses grupos (HANSEL; SCHMITZ, 2006). Ainda destacamos a presença de vasilha com a perfuração no bojo, que poderia indicar o uso de alça e a necessidade de transportá-la, incidindo, por conseguinte, na mobilidade do grupo.

Deve ser considerado no estudo a proximidade espacial dos sítios SA I e SA II e o tipo de subsistência praticado no litoral. É possível que se tratem de áreas com práticas de atividades 
distintas, uma relacionada ao uso de técnicas para exploração do ambiente fluviomarinho e outro exclusivo do ambiente marinho. Logo, explicar-se-ia um quantitativo menor de cerâmica no sítio SA I e a ausência de vasilha de tamanho pequeno em relação ao sítio SA II. Essa hipótese de áreas de atividade distintas é reforçada pelo quantitativo da coleção lítica, pois, no sítio SA I foram coletadas 180 peças líticas, enquanto que, no sítio SA II, foi coletada uma amostra de 16.278 peças líticas (SOUSA, 2011).

As semelhanças entre os sítios apontaram para as mesmas escolhas tecnológicas na produção e uso da cerâmica, o que pode indicar um mesmo sistema técnico, todavia, faz-se necessário confrontar os dados com datações absolutas.

No Nordeste do Brasil são encontradas a cerâmica Tupiguarani, amplamente conhecida, e a cerâmica da fase Papeba. Esta última foi identificada primeiramente no litoral do Rio Grande do Norte e caracterizada por Nássaro Nasser (1974) como: uma cerâmica de paredes finas, antiplástico de areia com textura grosseira, tratamento de superfície pintado e alisado, formas arredondadas, perfuração circular em apêndice no bojo, borda direta, boca circular e base arredondada.

Alguns elementos da cerâmica da fase Papeba foram identificados na cerâmica dos sítios de Sabiaguaba, contudo, existem visíveis variações na textura grosseira do antiplástico, na técnica do tratamento de superfície pintado e, sobretudo, na ausência de apêndice com furo. Entretanto, consideramos que para caracterizar um determinado Sistema Tecnológico é preciso definir como os diversos elementos estão organizados em cada estrutura, como, por exemplo, a inserção do material lítico desses sítios, o que permite estabelecer a sua relação com as formas de preparação e consumo dos alimentos por esses grupos.

A utilização da mesma metodologia em outros sítios é indispensável, pois amplia-se o número da amostra e poderá auxiliar na discussão sobre diferentes atividades ou sazonalidade da ocupação das dunas. Do mesmo modo, faz-se importante a aplicação de outras análises físico-químicas para identificar tipos de alimentos e função dos artefatos. Isto permitirá estabelecer de forma mais precisa aspectos da tecnologia de grupos que habitaram distintos ambientes do litoral, tanto em ambientes marinho e fluviomarinho.

A continuidade das pesquisas irá colaborar para identificar as áreas de captação de recursos alimentares e matéria-prima para a produção dos artefatos, definir o Sistema Tecnológico e, a partir deste, discutir aspectos sociais, mobilidade e áreas funcionais dos grupos litorâneos no Nordeste. 


\section{REFERÊNCIAS BIBLIOGRÁFICAS}

ALVES, Márcia Angelina. Estudo Técnico em cerâmica Pré-histórica do Brasil. Revista do Museu de Arqueologia e Etnologia, n. 4, p. 39-70, 1994.

BOËDA, Eric. Levallois: uma construção volumétrica, vários métodos, uma técnica. Canindé, n. 7, p. 37-77, 2006.

BRÉZILLON, Michel Nacu. La denomination des objets de pierre taillée: Matérieux pour un vocabulaire des préhistoriens de langue française. Paris, Editions Du Centre National de la Recherche Scientifique, 1968.

BROCHADO, José Proenza. Alimentação na floresta tropical. Caderno n. 2. Porto Alegre: Editora da Universidade Federal de Rio Grande do Sul, 1977.

BUTZER, Karl. Arqueología - Una ecología del hombre: Método y teoría para un enfoque contextual. Barcelona: Ediciones Bellaterra, 1989.

CASTRO, Viviane Maria Cavalcanti de. Sítio Cana Brava: contribuição ao estudo dos grupos ceramistas pré-históricos do sudeste do Piauí. Dissertação (Mestrado em História). Universidade Federal de Pernambuco, Recife, 1999.

CONKEY, Margaret. Experimenting with style in archaeology: some historical and theoretical. In: CONKEY, Margaret e HASTORF, Christine (org). The uses of style in archaeology. New York: Universidade de Cambridge, p. 5-17, 1990.

DIAS, Adriana Schmidt. Sistema de Assentamento e Estilo Tecnológico: Uma Proposta Interpretativa para a Ocupação Pré-colonial do Alto Vale dos Sinos, Rio Grande do Sul. Tese (Doutorado em Arqueologia). Universidade de São Paulo, São Paulo, 2003.

FAGUNDES, Marcelo. Sítio Rezende: das cadeias operatórias ao estilo tecnológico - um estudo de dinâmica cultural no médio vale do Paraíba, Centralina, Minas Gerais. Dissertação (Mestrado em Arqueologia). Universidade de São Paulo, São Paulo, 2004.

HANSEL, Fabricio Augusto e SCHMITZ, Pedro Ignácio. Classificação e interpretação dos resíduos orgânicos preservados em fragmentos de cerâmica arqueológica por Cromatografia Gasosa e Cromatografia Gasosa - Espectrometria de Massas. Pesquisas, n. 63, p. 81-112, 2006.

INIZAN, Marie-Louise; REDURON-BALLINGER, Michèle; ROCHE, Hélène; TIXIER, Jacques. Technologie de la pierre taillée. Meudon: C.R.E.P., 1995.

LA SALVIA, Fernando e BROCHADO, José Proença. Cerâmica Guarani. Porto Alegre: Posenato Arte e Cultura, 1989.

LEMONNIER, Pierre. L`etude des systemes techniques, une urgence en technologie culturelle. Techniques et Culture. v. 1, p. 11 - 34, 1983.

LEROI-GOURHAN, André. Evolução e técnica II (o meio e a técnica). Lisboa: Edições 70, 1984.

LLAMAZARES, Ana Maria e SLAVUTSKY, Ricardo. Paradigmas estilísticos en perspectiva histórica: del normativismo culturalista a las alternativas pos-sistémicas. Boletín de Antropología Americana, n. 22, p. 21-45, 1990. 
MACHADO, Daniel Luna e NOBRE, João Nilo. Relatório do Programa de Resgate Arqueológico na área de intervenção da rodovia CE 025/040 - municípios de Fortaleza e Eusébio - Ceará. Instituto Cobra Azul, 2017.

MEIRELES, Antonio Jeovah de Andrade, SILVA, Edson Vicente da, RAVENTOS, Jordi Serra. Geomorfologia e dinâmica ambiental da planície litorânea entre as desembocaduras dos rios Pacotí e Ceará, Fortaleza - Ceará. Revista Geo Notas. Maringá, v. 5, n. 1, Jan/Fev/ Mar 2001. Disponível em: <http://www.dge.uem.br/geonotas/vol5-1/meireles.shtml>. Acessado em: 01/07/2007.

MEGGERS, Betty Jane e EVANS, Clinfford. Como interpretar a linguagem da cerâmica. Washington: Smithsonian Institution, 1970.

NASSER, Nássaro de Souza. Novas contribuições à arqueologia do Rio Grande do Norte. Programa Nacional de Pesquisas Arqueológicas - Quinto ano - 1969 - 1970, p. 155 - 166, 1974. (Publicação avulsas, 26).

OLIVEIRA, Cláudia Alves de. A cerâmica pré-histórica no Brasil: Avaliação e proposta. Dissertação (Mestrado em História). Universidade Federal de Pernambuco, Recife, 1990.

OLIVEIRA, Cláudia Alves de. Estilos tecnológicos da cerâmica pré-histórica no Sudeste do Piauí Brasil. Tese (Doutorado em Arqueologia). Universidade de São Paulo, São Paulo, 2000.

OLIVEIRA, Cláudia Alves de. Os ceramistas pré-históricos do sudeste do Piauí - Brasil: estilos e técnicas. FUMDHAMENTOS III, v. 1, p. 57-127, 2003.

OLIVEIRA, Cláudia Alves de. As prioridades das escolhas técnicas. In: LOURES DE OLIVEIRA, Ana Paula de Paula (org.). IN: Arqueologia e patrimônio da Zona da Mata mineira: Carangola. Juiz de Fora: MAEA/UFJF, 2008, p. $153-167$.

OLIVEIRA, Cláudia Alves de. As fronteiras tecnológicas de grupos pré-históricos ceramistas do Nordeste. IN: Oliveira, Ana Paula de Paula Lourdes (org.). Estado da arte das pesquisas arqueológicas sobre a Tradição Tupiguarani. Juiz de Fora: EDUFJF, 2009, p. 131-150.

ORTON, Clive; TYERS, Paul; VINCE, Alan. La cerámica en arqueología. Trad. Rocío Barceló e Juan A. Barceló. Barcelona: Crítica, 1997.

PFAFFENBERGER, Bryan. Social Anthropology of Technology. Annual Review of Anthropology, v. 21, p. $491-516,1992$.

PINHEIRO, Bruno Carlos Alves e HOLANDA, José Nilson França. Efeito da temperatura de queima em algumas propriedades mecânicas de cerâmica vermelha. Cerâmica, n. 56, p. 237-243, 2010. Disponível em: <http://www.scielo.br/pdf/ce/v56n339/a0556339.pdf >. Acessado em: 01/09/2008.

PREFEITURA MUNICIPAL DE FORTALEZA. Plano de Manejo do Parque Natural Municipal das Dunas de Sabiaguaba (PNMDS) e Área de Proteção Ambiental de Sabiaguaba (APA). Fortaleza, 2010.

Projeto Ponte sobre o Rio Cocó e avenida de ligação: salvamento arqueológico do sítio Sabiaguaba Fortaleza - Ceará. Fundação Seridó, 2003.

RYE, Owen S. Pottery technology: Principles and reconstruction. (Manual son Archaeology 4). Washington DC: Smithsonian Institution Press, 1981. 
SACKETT, James Robert. Style and ethnicity in archeology: the case for isochrestism. IN: CONKEY, Margaret e HASTORF, Christine (org). The uses of style in archaeology. New York. University de Cambridge, 1990, p. 32-43.

SCHIFFER, Michael Brian. Archaeological context and systemic context. American Antiquity, v. 37, n. 2, p. 156-165, 1972.

SCHIFFER, Michael Brian e SKIBO, James M. The Explanation of Artifact Variability. American Antiquity, v.62, n.1, p. 27-50, 1997.

SHEPARD. Ana. Ceramics for the Archaeologist. Washington D.C: Camegie Institution of Washington. 1961.

SILVA, Fabíola Andréa. As tecnologias e seus significados. Canindé, n. 2, p. 119 - 138, 2002.

SILVA, Suely Gleyde Amâncio. Influência na evolução costeira holocênica na ocupação da costa do estado de Sergipe por grupos sambaquieiros. Dissertação (Mestrado em Ciências Geológicas). Universidade Federal da Bahia, Salvador, 2001.

SOUSA, Luci Danielli Avelino de. Os grupos pré-históricos ceramistas da praia de Sabiaguaba, Fortaleza/CE-Brasil. Dissertação (Mestrado em Arqueologia). Universidade Federal de Pernambuco, Recife, 2011.

WOODWARD, Kathryn. Identidade e diferença: uma introdução teórica e conceitual. IN: SILVA, Tomaz Tadeu da; HALL, Studart; WOODWARD, Kathryn (org.). Identidade e diferença: A perspectiva dos Estudos Culturais. 9a ed. Petrópolis: Vozes, 2009, p. 07-72. 